\title{
Effects of art/design education on meta-esthetics consciousness of fine arts students
}

\author{
Eylem TATAROGLU \\ Baskent University, Fine Arts Design and Architecture Faculty, Baglica Campus, Eskisehir Yolu 20. Km, 06870 \\ Etimesgut, Ankara, Turkey. \\ Received 17 November, 2014; Accepted 26 February, 2015
}

\begin{abstract}
The objectives of the present study were to determine the consciousness and sensitivity levels of Fine Arts students about the meta-esthetics as a consumer and producer and to determine the effects of the courses they took on their meta-esthetic consciousness. The research universe was composed of fine art faculties of the foundation universities located in Ankara during the academic year of 2013-2014. The research sample was composed of 126 students enrolled at Fine Arts Design and Architecture Faculty of Başkent University. During this academic year, there were 437 students in the faculty. In this study, production-consumption relationships were evaluated within the perspective of whether or not knowing meta-esthetics and development of esthetic awareness will be able to meet the demands of the people in the $21^{\text {st }}$ century.
\end{abstract}

Key words: Meta esthetics, art and design education, meta esthetics in fine arts education.

\section{INTRODUCTION}

Sensitivity can be defined as to be sensitive, susceptible and delicate. It is not possible without the action of recognition. Sensitivity is developed as a response to a case when the impacts of the case are sensed or known. The target in art education is highly complex and multistage education and creativity processes include primarily "awareness", "participation"; then "choosing the best to express oneself along with the personal characteristics and experiences" and "expressing oneself". The creativity, known as an ability which is not gained or learned afterwards, is only possible with proper conditions and quality art or design education and training.

Creativity depends on culture. Such dependence was expressed by Robinson (2008) as: "Cultural conditions may trigger or kill creativity. Creative thoughts do not reside in an empty space. Thoughts, works and creations of other people provoke the individual creativity. We have to climb over the shoulders of others to see further. Such a case is valid in all areas including, science, technology, sports, fashion, music, design, and etc. Human intelligence is a deep and comprehensive creator" (p.19).

Within the art/design education, art/design training, especially mentioned after the 1960s, has brought the discipline-oriented programs into agenda. Art training encompasses the disciplines of esthetics, art history, criticism and handcrafts and especially emphasizes the

E-mail: eta ta roglu@ba skent.edu.tr, epeskersoy@gmail.com. Tel: +90 312246 66 66/2060, +90 5534810780. Fax: +903122466639.

Authors agree that this artic le remain pemanently open access under the terms of the Creative Commons Attribution License 4.0 Intemational Lic ense 
discipline of esthetics. Boydaş (2006) pointed out such a case as: "The thing complying with the logic of art is esthetics apart from the workers of philosophers and scientist, the unique objective of esthetics to be considered all the time is beauty" (p. 5).

\section{CONCEPTUAL FRAMEWORK}

\section{The science of esthetics}

Esthetic in full-sense means the science of sensation, the science of sense. Esthetic is considered as the science related to sensible perception and sensitivity (Tunali, 1998, p.1).

Ranciére (2001) in his work pointed out the relationships of esthetics with the mind and presented the following definition: "Esthetic points out a mentality opening itself to artistic choices and trying to express why they are intellectual choices" (p. 9).

Another researcher pointing out the significance of thoughts is Herbert Read. Read (1978) in his work, expressed that foundations of civilizations lied in sensetions, not in mind. According to Read, unless how to use senses is not learned, it is impossible to move forward, even impossible to create biological conditions to survive (p.193).

\section{Esthetic reality}

Esthetic reality is an esthetic philosophy composed of heterogeneous esthetic problems and creates the foundations of today's ontology of esthetics. Every esthetic phenomenon is necessarily related to a subject. This subject participates in the integrity of the esthetic phenomenon as an esthetic attitude and as an esthetic sensation asset (Tunali, 1998, p.18).

Esthetic asset does not rely only on the existence of the subject. In esthetic phenomenon, there is another asset that the subject is oriented to on the face of the subject, which participated in this phenomenon: Esthetic object (Tunali, 1998, p.47). Another asset creating the esthetic entity is the esthetic value or the beauty. Subjectobject relationship is objectified as a judgment: Esthetic judgment (Tunali, 1998, p.21).

\section{Meta esthetics}

It is required to know the fundamental basis of Marxist esthetic to know about meta-esthetics. According to Marxist esthetics, a subject comprehends an object as a sole sensual-tangible object and such an object can be an esthetic object only when an esthetic pleasure is sensed from this object. As mentioned in the work of Tunali (2003), Marxist esthetic relies on a humanitarian culture base (p.9).

It is required to know about the Marxist philosophy well enough to resolve the Marxist esthetics. Marxist philosophy is dialectic materialism; it is basically dialectic. It is a great idealistic philosophy started by Kant, moved through Fichte and Schelling and extended to Hegel (Tunali, 2003, p.12).

Tunali (2009), in his work put forward the relationship between an industrial good and social status: "The industry trying to meet the entire demands of the society through serial production is effective in determination of social status in the society despite the democratic trend in this desire. The interests of social classes in industrial goods are directly related to their income levels" (p.100) . Another issue was pointed about by Read (1978) in the following fashion: "A hundred years ago, the important point was how to inspect the machine. The machine was a monster receiving raw materials from one end and ejecting finished goods from the other end. However, the finished good should have attracted the attentions of the consumers with its grace, ornament, and color. The capitalists of that age were aware of the fact that the art was a commercial factor. When the other things were equal, the most "artistic" product was going to capture the market (p.19).

Meta esthetics originates form the meta form of products and determined by the change value functionally. Haug (1997) defines meta-esthetics and its functions as follows:

"On the one hand, there is the "beauty" in another words an appearance appealing to the senses; on the other hand there is a design impelling the purchasing reflects of the observes to own that meta. Well-appearance of the meta to the people puts the sensual perceptions of them into action and then sensual benefits determine them. Conversion of beneficial objects of the world into meta triggers instinctual responses and consequently functional tools to renew or reshape not only the humanitarian sensitivity but also the world sensual objects occurs. Therefore, the concept of "reshape of sensitivity" becomes a significant issue" (p.14).

Because of the above specified reasons, it is necessary to head towards an art education perception supporting and allowing formation of an art/design object that is able to be represented technology, fashion and design areas and able form a tradition, not excluding the cultural items from the mass where everything is commoditized and served to use with sparkling appearance and slogans.

\section{Objective of the study}

The objective of the present study was to determine the effects of demographic characteristics and art/design education of the students studying at art and design 
Table 1. Frequency tables of demographic characteristics of participants based on gender.

\begin{tabular}{llllll}
\hline & & Frequency & Percent & Valid Percent & Cumulative Percent \\
\hline \multirow{4}{*}{ Valid } & Female & 76 & 60.3 & 60.3 & 60.3 \\
& Male & 50 & 39.7 & 39.7 & 100.0 \\
& Total & 126 & 100.0 & 100.0 & \\
\hline
\end{tabular}

faculties on their awareness about meta-esthetics.

\section{Significance of the study}

The present study was designed based on the doctorate thesis of the researcher defended and successfully passed in 2009 (Peşkersoy, 2009). There were 409 participant students being the subject of the relevant doctorate thesis and all of them were in senior year of their studies at art and design teacher departments of education faculties. To compare the results, it was suggested that artist/designer candidates were evaluated with a similar scale and basis.

Approaches of current educational policies and educational programs of every level to be conscious are notable. Raising members of a society, which is conscious about production and consuming, is regarded as passive part of the "global culture" of the $21^{\text {st }}$ century, but not as an active part.

\section{METHOD}

In this section, "research model", "universe and sample", "data collection techniques", "development of data collection tools" and "data analyses" are provided.

\section{Research model}

The present research was designed based on "general screening model"; and "school survey" method was used as the description method.

\section{Universe and sample}

The research universe was composed of fine art faculties of the foundation universities located in Ankara during the academic year of 2013-2014. In this category, there were 6 universities offering fine arts education. The research sample was composed of 126 students studying at Fine Arts Design and Architecture Faculty of Baskent University. During this academic year, there were 437 students in the faculty. While determining the research sample, the students who already took the course of "basic art/design education" and "esthetics" were taken into consideration.

\section{Data collection techniques}

Sample students were subjected to an attitude scale. With the developed attitude scale, the status of meta esthetics in art/design education; belief about the necessity of meta esthetics in terms of esthetic consciousness; awareness about the relationships of meta esthetics with fashion, design and technology were determined.

\section{Development of data collection tools}

Data collection tool turned out to be the adaptation of attitude scale articles which were used in 2009 and passed validity-reliability tests to the design education. The revised scale was also subjected to validity-reliability test and the scale validity and reliability were proven by scientific data analysis.

\section{Data analysis}

Data analyses were performed by SPSS 11.0 statistical software. In data analyses, initially frequency tables belonging to a variable were created. Between the items that might be interrelated formed the crosswise tables. Additionally, "RXC Cross Table" was technologocally applied to the mass counted in the Khi-square analysis technics for the purpose of independence controlling. Then the symmetric measurements of the cross tables that formed on SPSS were carried out. A statistical hypothesis test was applied to reveal the interrelationship between the matters. Spearman Correlation coefficient was considered to assess the level of relationship. Statistical hypotheses were applied to put forward the status of relationship between the related items. The hypothesis was tested according to the " $p$ value" of these measurements. The hypothesis, $H_{0}$, was rejected since $P=0.000<\alpha=0.05$.

\section{RESULTS AND DISCUSSION}

All the responses given to attitude scale items were "valid".

\section{Frequency tables of demographic characteristics}

Of the students who participated in the attitude scale, $60.3 \%$ were females and $39.7 \%$ were males (Table 1 ).

Of the participant students, $15.1 \%$ was between $18-20$ years of age; $78.6 \%$ was between $21-25$ years; $5.2 \%$ was between $26-30$ years and $0.8 \%$ was between $31-35$ years of age (Table 2).

Of the participant students, $29.4 \%$ enrolled in Graphic Design Program of Visual Arts and Design Department, $69.8 \%$ enrolled in Interior Architecture and Environmental Design Department and only $0.8 \%$ enrolled in Fashion and Textile Department (Table 3).

Of the participant students, $36.5 \%$ was enrolled in freshman year $\left(1^{\text {st }}\right.$ year $), 20.6 \%$ in sophomore year $\left(2^{\text {nd }}\right.$ year), $16.7 \%$ in junior year ( $3^{\text {rd }}$ year) and $26.2 \%$ in senior 
Table 2. Demographic characteristics of participants based on age.

\begin{tabular}{cccccc}
\hline & Frequency & Percent & Valid Percent & Cumulative Percent \\
\hline 18 & 1 & .8 & .8 & .8 \\
19 & 5 & 4.0 & 4.0 & 4.8 \\
20 & 13 & 10.3 & 10.3 & 15.1 \\
21 & 15 & 11.9 & 11.9 & 27.0 \\
22 & 21 & 16.7 & 16.7 & 43.7 \\
23 & 30 & 23.8 & 23.8 & 67.5 \\
Valid & 17 & 13.5 & 13.5 & 81.0 \\
24 & 16 & 12.7 & 12.7 & 93.7 \\
25 & 2 & 1.6 & 1.6 & 95.2 \\
26 & 1 & .8 & .8 & 96.0 \\
27 & 2 & 1.6 & 1.6 & 97.6 \\
29 & 2 & 1.6 & 1.6 & 99.2 \\
30 & 1 & .8 & .8 & 100.0 \\
& 32 & 126 & 100.0 & 100.0 & \\
\hline
\end{tabular}

Table 3. Frequency tables of participants' study program.

\begin{tabular}{|c|c|c|c|c|c|}
\hline & & Frequency & Percent & Valid percent & Cumulative percent \\
\hline \multirow{4}{*}{ Valid } & Graphic and design program & 37 & 29.4 & 29.4 & 29.4 \\
\hline & Interior architecture and environmental design department & 88 & 69.8 & 69.8 & 99.2 \\
\hline & Fashion and textile department & 1 & .8 & .8 & 100.0 \\
\hline & Total & 126 & 100.0 & 100.0 & \\
\hline
\end{tabular}

year $\left(4^{\text {th }}\right.$ year) (Table 4$)$.

With regard to education levels of the mothers of the participant students, $2.4 \%$ did not have any formal education, $12.7 \%$ had primary and secondary school education, $43.7 \%$ had high school education, $4.8 \%$ had vocational collage education, $30.2 \%$ had undergraduate education and $6.3 \%$ had graduate education (Table 5).

With regard to education levels of the fathers of the participant students, $8.7 \%$ did not have any formal education, $34.2 \%$ had primary and secondary school education, $30.2 \%$ had high school education, $6.3 \%$ had vocational collage education, $38.9 \%$ had undergraduate education and $11.9 \%$ had graduate education (Table 6 ).

With regard to attitudes of the families while raising the participant students, $73 \%$ was democratic, $20.6 \%$ was authoritarian and $6.3 \%$ was careless (Table 7 ).

Of the participant students, a large portion $(59.5 \%)$ was satisfied with the department that they are enrolled, $31.7 \%$ was partially satisfied and $8.7 \%$ was not satisfied with the department (Table 8).

Of the participant students, $2.4 \%$ indicated that the department/area they study was above their expectations, $50.8 \%$ stated that the department was suitable to their expectations and $46.8 \%$ stated that the department was below their expectations (Table 9).

With regard to dwelling units where the participant students received their secondary education, $77 \%$ was in metropolises, $16.7 \%$ in provinces and $6.3 \%$ was in counties (Table 10).

\section{Frequency tables of section two (Opinions about course contents)}

Item 1: Art and design courses teach me artistic design principles both theoretically and practically.

Of the participant students, $57.1 \%$ agreed that art and design courses teach them artistic design principles both theoretically and practically. About $24.6 \%$ of them were undecided. By taking undecided ones as negative, the rate of students indicating negative opinion for this item sums up to $44.9 \%$. In this case, it is possible to state that almost half of the students indicated supportive opinion about the subject and the other half indicated negative opinion for this item (Table 11).

Item 2: Art education courses do not have contents that will enable me to use my creativity and composition knowledge.

The total of the undecided and supportive students were $56.4 \%$ and participant students agreed that art education courses have contents that enable them to use their 
Table 4. University level of students.

\begin{tabular}{cccccc}
\hline & Frequency & Percent & Valid percent & Cumulative percent \\
\hline \multirow{4}{*}{ Valid } & 1 & 46 & 36.5 & 36.5 & 36.5 \\
& 2 & 26 & 20.6 & 20.6 & 57.1 \\
& 3 & 21 & 16.7 & 16.7 & 73.8 \\
& 4 & 33 & 26.2 & 26.2 & 100.0 \\
& Total & 126 & 100.0 & 100.0 & \\
\hline
\end{tabular}

Table 5. Educational level of the participant students' mothers.

\begin{tabular}{llcccc}
\hline & Frequency & Percent & Valid percent & Cumulative percent \\
\hline \multirow{2}{*}{ Valid } & 3 & 2.4 & 2.4 & 2.4 \\
& Illiterate & 12 & 9.5 & 9.5 & 11.9 \\
Primary school & 4 & 3.2 & 3.2 & 15.1 \\
Secondary school & 55 & 43.7 & 43.7 & 58.7 \\
& High school & 6 & 4.8 & 4.8 & 63.5 \\
& Vocational Collage & 68 & 30.2 & 30.2 & 93.7 \\
Undergraduate & 38.3 & 6.3 & 100.0 \\
Graduate & 8 & 6.3 & 100.0 & \\
Total & 126 & 100.0 & &
\end{tabular}

Table 6. Educational level of the participant students' fathers.

\begin{tabular}{|c|c|c|c|c|c|}
\hline & & Frequency & Percent & Valid percent & Cumulative percent \\
\hline \multirow{7}{*}{ Valid } & Primary school & 11 & 8.7 & 8.7 & 8.7 \\
\hline & Secondary school & 5 & 4.0 & 4.0 & 12.7 \\
\hline & High school & 38 & 30.2 & 30.2 & 42.9 \\
\hline & Vocational Collage & 8 & 6.3 & 6.3 & 49.2 \\
\hline & Undergraduate & 49 & 38.9 & 38.9 & 88.1 \\
\hline & Graduate & 15 & 11.9 & 11.9 & 100.0 \\
\hline & Total & 126 & 100.0 & 100.0 & \\
\hline
\end{tabular}

Table 7. Attitudes of the participant students' mothers/fathers.

\begin{tabular}{llcccc}
\hline & & Frequency & Percent & Valid percent & Cumulative percent \\
\hline \multirow{4}{*}{ Valid } & Democratic & 92 & 73.0 & 73.0 & 73.0 \\
& Authoritarian & 26 & 20.6 & 20.6 & 93.7 \\
& Careless & 8 & 6.3 & 6.3 & 100.0 \\
& Total & 126 & 100.0 & 100.0 & \\
\hline
\end{tabular}

Table 8. Students' satisfaction with departments.

\begin{tabular}{|c|c|c|c|c|c|}
\hline & & Frequency & Percent & Valid percent & Cumulative percent \\
\hline Valid & Yes & 75 & 59.5 & 59.5 & 59.5 \\
\hline Partially & & 40 & 31.7 & 31.7 & 91.3 \\
\hline No & & 11 & 8.7 & 8.7 & 100.0 \\
\hline Total & & 126 & 100.0 & 100.0 & \\
\hline
\end{tabular}


Table 9. Area-expectation relationships.

\begin{tabular}{llcccc}
\hline & Frequency & Percent & Valid percent & Cumulative percent \\
\hline \multirow{4}{*}{ Valid } & Above my expectations & 3 & 2.4 & 2.4 & 2.4 \\
& Comply with my expectations & 64 & 50.8 & 50.8 & 53.2 \\
& Below my expectations & 59 & 46.8 & 46.8 & 100.0 \\
& Total & 126 & 100.0 & 100.0 & \\
\hline
\end{tabular}

Table 10. The place where participant students received secondary education.

\begin{tabular}{llcccc}
\hline & Frequency & Percent & Valid percent & Cumulative percent \\
\hline \multirow{4}{*}{ Valid } & Greater city & 97 & 77.0 & 77.0 & 77.0 \\
& Province & 21 & 16.7 & 16.7 & 93.7 \\
& Town & 8 & 6.3 & 6.3 & 100.0 \\
& Total & 126 & 100.0 & 100.0 & \\
\hline
\end{tabular}

Table 11. Students' opinions about art and design course contents.

\begin{tabular}{llcccc}
\hline & Frequency & Percent & Valid Percent & Cumulative Percent \\
\hline \multirow{6}{*}{ Valid } & Totally Disagree & 4 & 3.2 & 3.2 & 3.2 \\
& Disagree & 9 & 7.1 & 7.1 & 10.3 \\
& Undecided & 31 & 24.6 & 24.6 & 34.9 \\
& Agree & 72 & 57.1 & 57.1 & 92.1 \\
& Totally Agree & 10 & 7.9 & 7.9 & 100.0 \\
Total & 126 & 100.0 & 100.0 & \\
\hline
\end{tabular}

Table 12. Students' opinions about art education courses

\begin{tabular}{llcccc}
\hline & Frequency & Percent & Valid Percent & Cumulative Percent \\
\hline \multirow{6}{*}{ Valid } & Totally Disagree & 9 & 7.1 & 7.1 & 7.1 \\
& Disagree & 46 & 36.5 & 36.5 & 43.7 \\
& Undecided & 33 & 26.2 & 26.2 & 69.8 \\
& Agree & 31 & 24.6 & 24.6 & 94.4 \\
& Totally Agree & 7 & 5.6 & 5.6 & 100.0 \\
& Total & 126 & 100.0 & 100.0 & \\
\hline
\end{tabular}

creativity and composition knowledge. On the other hand, $43.6 \%$ of the students indicated their disagreement with this item (Table 12).

Item 3: I think we took appropriate art and design courses that can make us to play the role of an artist or designer properly, either as an art producer or consumer.

The ratio of the students thinking that they have taken appropriate courses allowing them to play the role of an artist or designer properly was $56.4 \%$. On the other hand, the sum of undecided and opponents was 43.7 for this item (Table 13).
Item 4: I think there is insufficient education on the significance and necessity of esthetic values in the characteristics of our culture.

With regard to item $4,49.2 \%$ of the students indicated positive opinions. On the other hand, undecided and negative opinions had a sum of $50.8 \%$. Almost half of the students indicated that the education they receive has insufficient esthetic value (Table 14).

Item 5: I think art educators exhibit sufficient sincerity and sensitivity in the teaching of art.

This item evaluates the sincerity and sensitivity of 
Table 13. Students' opinion about taking appropriate art and design courses.

\begin{tabular}{llccc}
\hline & Frequency & Percent & Valid Percent & Cumulative Percent \\
\hline \multirow{4}{*}{ Valid } & 3 & 2.4 & 2.4 & 2.4 \\
Disagree & 18 & 14.3 & 14.3 & 16.7 \\
Undecided & 34 & 27.0 & 27.0 & 43.7 \\
Agree & 64 & 50.8 & 50.8 & 94.4 \\
Totally Agree & 7 & 5.6 & 5.6 & 100.0 \\
Total & 126 & 100.0 & 100.0 & \\
\hline
\end{tabular}

Table 14. Students' opinions on esthetic values education.

\begin{tabular}{llcccc}
\hline & Frequency & Percent & Valid Percent & Cumulative Percent \\
\hline \multirow{6}{*}{ Valid } & Totally Disagree & 5 & 4.0 & 4.0 & 4.0 \\
& Disagree & 32 & 25.4 & 25.4 & 29.4 \\
Undecided & 27 & 21.4 & 21.4 & 50.8 \\
& Agree & 50 & 39.7 & 39.7 & 90.5 \\
& Totally Agree & 12 & 9.5 & 9.5 & 100.0 \\
& Total & 126 & 100.0 & 100.0 & \\
\hline
\end{tabular}

Table 15. Students' opinions about art educators' sincerity and sensitivity in the teaching of art.

\begin{tabular}{|c|c|c|c|c|c|}
\hline & & Frequency & Percent & Valid Percent & Cumulative Percent \\
\hline \multirow{6}{*}{ Valid } & Totally Disagree & 7 & 5.6 & 5.6 & 5.6 \\
\hline & Disagree & 16 & 12.7 & 12.7 & 18.3 \\
\hline & Undecided & 28 & 22.2 & 22.2 & 40.5 \\
\hline & Agree & 58 & 46.0 & 46.0 & 86.5 \\
\hline & Totally Agree & 17 & 13.5 & 13.5 & 100.0 \\
\hline & Total & 126 & 100.0 & 100.0 & \\
\hline
\end{tabular}

attitudes of art educators toward the students and courses. The ratio of the undecided ones and the students indicating negative opinions were $40.5 \%$. It is thought that such a ratio is significantly high for art educators (Table 15).

Item 6: I don't think esthetic and meta-esthetic topics are sufficiently included in the course contents of the education program that I attend.

This item questions the sufficiency of esthetic and metaesthetic topics within the education program. Of the participant students, $42 \%$ indicated insufficient placement of esthetic and meta-esthetic topics. The total of undecided ones and the rest was 58\% (Table 16).

\section{Frequency tables of section three (Opinions about consumption)}

Item 1: I don't feel uncomfortable about buying products which are distorted, whose advertisement is exaggerated and which are "nice" to my senses.

This item questions the purchasing behavior of students although they know that the advertisement is made by exaggerating or distorting their characteristics. Of the participant students, $51.2 \%$ indicated positive response, $24.6 \%$ was undecided and $23.8 \%$ indicated negative response to this item. The total of undecided ones and positive ones was $76.2 \%$. Such a case indicated that students were not sufficiently conscious about the training of their senses (Table 17).

Item 2: Appearance of a product I am going to purchase is more important than its functions.

This item questions the priority of the appearance and functions of a product in purchasing preferences. Of the participant students, $37.3 \%$ assigned priority to the appearance, $40.7 \%$ to the functions, and $22.2 \%$ was undecided between the appearance and function (Table 18). 
Table 16. Students' opinions about the inclusion of esthetic and meta-esthetic topics in the course contents of education program.

\begin{tabular}{llcccc}
\hline & Frequency & Percent & Valid Percent & Cumulative Percent \\
\hline \multirow{6}{*}{ Valid } & Totally Disagree & 5 & 4.0 & 4.0 & 4.0 \\
& Disagree & 32 & 25.4 & 25.4 & 29.4 \\
& Undecided & 36 & 28.6 & 28.6 & 57.9 \\
& Agree & 42 & 33.3 & 33.3 & 91.3 \\
& Totally Agree & 11 & 8.7 & 8.7 & 100.0 \\
& Total & 126 & 100.0 & 100.0 & \\
\hline
\end{tabular}

Table 17. Students' opinions about buying products which are distorted and whose advertisement is exaggerated.

\begin{tabular}{llccc}
\hline & Frequency & Percent & Valid Percent & Cumulative Percent \\
\hline Totally Disagree & 10 & 7.9 & 7.9 & 7.9 \\
Disagree & 20 & 15.9 & 15.9 & 23.8 \\
Valid & 31 & 24.6 & 24.6 & 48.4 \\
Undecided & 51 & 40.5 & 40.5 & 88.9 \\
Agree & 14 & 11.1 & 11.1 & 100.0 \\
Totally Agree & 126 & 100.0 & 100.0 & \\
Total & & & &
\end{tabular}

Table 18. Students' opinion about the priority of the appearance and functions of a product in purchasing preferences.

\begin{tabular}{llcccc}
\hline & Frequency & Percent & Valid Percent & Cumulative Percent \\
\hline \multirow{6}{*}{ Valid } & 16 & 12.7 & 12.7 & 12.7 \\
& Dotally Disagree & 35 & 27.8 & 27.8 & 40.5 \\
Undecided & 28 & 22.2 & 22.2 & 62.7 \\
Agree & 44 & 34.9 & 34.9 & 97.6 \\
& Totally Agree & 3 & 2.4 & 2.4 & 100.0 \\
Total & 126 & 100.0 & 100.0 & \\
\hline
\end{tabular}

Item 3: I care about buying products for which advertisement is made.

This item evaluates the role of advertisement in buying preferences of customers. Of the participant students, $54.1 \%$ preferred the advertised products, $44.4 \%$ indicated their disagreement with this item, and $21.4 \%$ was undecided about this item. The ratios were close to each other in this item (Table 19).

Item 4: I think the changes made only in the package of an item trick the consumers.

This item evaluates the effectiveness of changes in package of an item in convincing consumers. Of the participant students, $61.1 \%$ indicated that changes over the package of an item trick the consumers, $18.3 \%$ indicated negative opinion for this item and $27.8 \%$ was undecided on this item (Table 20).

Item 5: Because of art and design education I received, I look initially for the esthetic integrity and uniqueness in an item I purchase.

For this attitude scale evaluating the function of art/design education in purchase preferences, $78.2 \%$ looked for integrity and uniqueness, $19 \%$ was undecided and $12.7 \%$ indicated negative response (Table 21 ).

Item 6: I think the institutions providing basic art/design education and raising artist/designer are insufficient in raising conscious art consumers.

This item questions the role of the institutions raising artist/designer through providing basic art/design education in raising conscious art consumers. Of the participant 
Table 19. Students' opinion about buying products for which advertisement is made.

\begin{tabular}{llcccc}
\hline & Frequency & Percent & Valid Percent & Cumulative Percent \\
\hline \multirow{4}{*}{ Valid } & 14 & 11.1 & 11.1 & 11.1 \\
& Disagree & 42 & 33.3 & 33.3 & 44.4 \\
Undecided & 27 & 21.4 & 21.4 & 65.9 \\
Agree & 34 & 27.0 & 27.0 & 92.9 \\
Totally Agree & 9 & 7.1 & 7.1 & 100.0 \\
Total & 126 & 100.0 & 100.0 & \\
\hline
\end{tabular}

Table 20. Students' opinion about the changes made only in the package of an item.

\begin{tabular}{llcccc}
\hline & Frequency & Percent & Valid Percent & Cumulative Percent \\
\hline \multirow{4}{*}{ Totally Disagree } & 1 & .8 & .8 & .8 \\
Disagree & 13 & 10.3 & 10.3 & 11.1 \\
Undecided & 35 & 27.8 & 27.8 & 38.9 \\
Agree & 57 & 45.2 & 45.2 & 84.1 \\
Totally Agree & 20 & 15.9 & 15.9 & 100.0 \\
Total & 126 & 100.0 & 100.0 & \\
\hline
\end{tabular}

Table 21. Students' opinion about the esthetic integrity and uniqueness they look for in an item purchased.

\begin{tabular}{llccc}
\hline & Frequency & Percent & Valid Percent & Cumulative Percent \\
\hline Totally Disagree & 3 & 2.4 & 2.4 & 2.4 \\
Disagree & 13 & 10.3 & 10.3 & 12.7 \\
Valid & 24 & 19.0 & 19.0 & 31.7 \\
Undecided & 57 & 45.2 & 45.2 & 77.0 \\
Agree & 29 & 23.0 & 23.0 & 100.0 \\
Totally Agree & 126 & 100.0 & 100.0 & \\
Total & & &
\end{tabular}

students, $52.4 \%$ found these institutions insufficient, $29.4 \%$ was undecided and $18.3 \%$ did not find the institutions insufficient in raising conscious art consumers (Table 22).

\section{Frequency tables of section four (Opinions about production)}

Item 1: I hear the concept of "meta esthetics" for the first time.

Of the participant students, $56.4 \%$ indicated that they heard the concept of "meta esthetics" for the first time, $38.1 \%$ indicated that they did not hear the concept for the first time and $5.6 \%$ was undecided about this item (Table 23).

Item 2: I think esthetic appearance and functionality are equally and highly important in the design of every product with the intended use.
This item includes a comparative evaluation about the appearance and sales value of an item. Of the participant students, $76.2 \%$ indicated that appearance and sales value is equally and highly important, $11.9 \%$ was undecided and another $11.9 \%$ indicated negative response for this item (Table 24).

Item 3: In a product I present to express myself, I don't care about the interests and needs of the crowd with which I share that product.

This item evaluates the attitudes of a producer in meta production based on the interest and needs of the consumers. Of the participant students, $28.5 \%$ indicated that they did not care about the consumers' interests and needs, $57.2 \%$ indicated that they cared about their interests and needs and $14.3 \%$ was undecided about this item. About $42.8 \%$ was negative or undecided about interests and needs matter and this is challenging ethically (Table 25).

Item 4: The advertisement of a product I designed may 
Table 22. Students' opinion about institutions providing basic art/design education and raising artist/designer.

\begin{tabular}{llcccc}
\hline & Frequency & Percent & Valid Percent & Cumulative Percent \\
\hline \multirow{6}{*}{ Valid } & 2 & 1.6 & 1.6 & 1.6 \\
& Totally Disagree & 21 & 16.7 & 16.7 & 18.3 \\
& Disagree & 37 & 29.4 & 29.4 & 47.6 \\
& Undecided & 43.1 & 34.1 & 81.7 \\
& Agree & 18.3 & 18.3 & 100.0 \\
& Totally Agree & 23 & 100.0 & \\
Total & 126 & 100.0 & & & \\
\hline
\end{tabular}

Table 23. Students' opinion about the concept of "meta esthetics" for the first time.

\begin{tabular}{llcccc}
\hline & Frequency & Percent & Valid Percent & Cumulative Percent \\
\hline Totally Disagree & 13 & 10.3 & 10.3 & 10.3 \\
Disagree & 35 & 27.8 & 27.8 & 38.1 \\
Valid & 7 & 5.6 & 5.6 & 43.7 \\
Undecided & 53 & 42.1 & 42.1 & 85.7 \\
Agree & 18 & 14.3 & 14.3 & 100.0 \\
Totally Agree & 126 & 100.0 & 100.0 & \\
Total & & & &
\end{tabular}

Table 24. Students' opinion about esthetic appearance and functionality.

\begin{tabular}{llllll}
\hline & Frequency & Percent & Valid Percent & Cumulative Percent \\
\hline \multirow{4}{*}{ Valid } & Totally Disagree & 4 & 3.2 & 3.2 & 3.2 \\
Disagree & 11 & 8.7 & 8.7 & 11.9 \\
Undecided & 15 & 11.9 & 11.9 & 23.8 \\
Agree & 67 & 53.2 & 53.2 & 77.0 \\
& Totally Agree & 29 & 23.0 & 23.0 & 100.0 \\
Total & 126 & 100.0 & 100.0 & \\
\hline
\end{tabular}

Table 25. Students' opinion about caring about the interests and needs of the crowd buying a product.

\begin{tabular}{llllll}
\hline & Frequency & Percent & Valid Percent & Cumulative Percent \\
\hline \multirow{6}{*}{ Valid } & Totally Disagree & 22 & 17.5 & 17.5 & 17.5 \\
& Disagree & 50 & 39.7 & 39.7 & 57.1 \\
& Undecided & 18 & 14.3 & 14.3 & 71.4 \\
& Agree & 28 & 22.2 & 22.2 & 93.7 \\
& Totally Agree & 8 & 6.3 & 6.3 & 100.0 \\
& Total & 126 & 100.0 & 100.0 & \\
\hline
\end{tabular}

be deceptive and may not sufficiently reflect the product I designed. However, I don't feel uncomfortable if the advertisement is effective and able to meet me with the target market and the money.

This item was placed into the scale to evaluate ethical attitudes of the students who are raised as designers within the triangle of their designs, advertisement and money. Of the participant students, $38.1 \%$ preferred to reach money and target mass, $32.5 \%$ indicated their discomforts and $29.4 \%$ was undecided in this item. In this item, $61.9 \%$ majority was remarkable and unfortunately they were putting a meta ahead of the value (Table 26).

Item 5: It is possible to direct people without being noticed and to impose on them the elements of a culture. 
Table 26. Students' opinion about advertisement of a product they design.

\begin{tabular}{llcccc}
\hline & Frequency & Percent & Valid percent & Cumulative percent \\
\hline Valid & Totally Disagree & 10 & 7.9 & 7.9 & 7.9 \\
& Disagree & 31 & 24.6 & 24.6 & 32.5 \\
Undecided & 37 & 29.4 & 29.4 & 61.9 \\
Agree & 38 & 30.2 & 30.2 & 92.1 \\
Totally Agree & 10 & 7.9 & 7.9 & 100.0 \\
Total & 126 & 100.0 & 100.0 & \\
\hline
\end{tabular}

Table 27. Students' opinion of the possibility of controlling people without being noticed.

\begin{tabular}{llcccc}
\hline & Frequency & Percent & Valid Percent & Cumulative Percent \\
\hline Valid & Totally Disagree & 1 & .8 & .8 & .8 \\
& Disagree & 7 & 5.6 & 5.6 & 6.3 \\
Undecided & 23 & 18.3 & 18.3 & 24.6 \\
Agree & 64 & 50.8 & 50.8 & 75.4 \\
Totally Agree & 31 & 24.6 & 24.6 & 100.0 \\
Total & 126 & 100.0 & 100.0 & \\
\hline
\end{tabular}

Table 28. Students' opinion of being a famous artist/designer.

\begin{tabular}{llcccc}
\hline & Frequency & Percent & Valid Percent & Cumulative Percent \\
\hline Valid & Totally Disagree & 1 & .8 & .8 & .8 \\
& Disagree & 13 & 10.3 & 10.3 & 11.1 \\
Undecided & 18 & 14.3 & 14.3 & 25.4 \\
Agree & 36 & 28.6 & 28.6 & 54.0 \\
Totally Agree & 58 & 46.0 & 46.0 & 100.0 \\
Total & 126 & 100.0 & 100.0 & \\
\hline
\end{tabular}

This item was written to bring anesthetic impact of meta esthetic forward. Of the participant student, $85.4 \%$ approved these characteristics, $18.3 \%$ was undecided and $6.4 \%$ denied this characteristic (Table 27 ).

Item 6: I wish to be an artist/designer known by everybody.

This item evaluates the attitudes of the students about fame. Of the participant students, $74.6 \%$ cared about fame, $14.3 \%$ was undecided and $11.1 \%$ did not care about being an artist/designer known by everybody (Table 28).

\section{Frequency tables of section five (Opinions about creativity)}

Item 1: I think that in order to develop a need for something requires creativity.

This item evaluates the effects of creativity on manipula- tions of meta esthetics for human needs. Of the participant students, $84.1 \%$ indicated the effects of creativity, $8 \%$ indicated ineffectiveness of creativity and $7.9 \%$ was undecided about this item (Table 29 ).

Item 2: I think knowledge of meta esthetics by creative individuals is both necessary and significant in culture transfer.

This item investigates the role of meta-esthetics in culture transfer and none of the students indicated a total disagreement absolutely about this item. Of the participant students, $70.7 \%$ agreed with this opinion, $26.2 \%$ was undecided and only $3.2 \%$ indicated disagreement with this item (Table 30).

Item 3: I think advertisement is necessary to introduce a product that I produced with my creativity (artwork/design product) to large masses.

This item evaluates the effects of advertisement on the publicity of a product. Of the participant students, $75.5 \%$ 
Table 29. Students' opinion about creativity.

\begin{tabular}{llcccc}
\hline & Frequency & Percent & Valid Percent & Cumulative Percent \\
\hline \multirow{2}{*}{ Valid } & Totally Disagree & 4 & 3.2 & 3.2 & 3.2 \\
& Disagree & 6 & 4.8 & 4.8 & 7.9 \\
& Undecided & 10 & 7.9 & 7.9 & 15.9 \\
Agree & 66 & 52.4 & 52.4 & 68.3 \\
Totally Agree & 40 & 31.7 & 31.7 & 100.0 \\
& Total & 126 & 100.0 & 100.0 & \\
\hline
\end{tabular}

Table 30. Students' opinion about the knowledge of meta esthetics by creative individuals.

\begin{tabular}{llcccc}
\hline & Frequency & Percent & Valid Percent & Cumulative Percent \\
\hline \multirow{2}{*}{ Valid } & Disagree & 4 & 3.2 & 3.2 & 3.2 \\
& Undecided & 33 & 26.2 & 26.2 & 29.4 \\
& Agree & 68 & 54.0 & 54.0 & 83.3 \\
Totally Agree & 21 & 16.7 & 16.7 & 100.0 \\
Total & 126 & 100.0 & 100.0 & \\
\hline
\end{tabular}

Table 31. Students' opinion about the effects of advertisement on the publicity of a product.

\begin{tabular}{|c|c|c|c|c|c|}
\hline & & Frequency & Percent & Valid Percent & Cumulative Percent \\
\hline \multirow[t]{5}{*}{ Valid } & & 10 & 7.9 & 7.9 & 7.9 \\
\hline & Disagree & 21 & 16.7 & 16.7 & 24.6 \\
\hline & Undecided & 63 & 50.0 & 50.0 & 74.6 \\
\hline & Agree & 32 & 25.4 & 25.4 & 100.0 \\
\hline & Total & 126 & 100.0 & 100.0 & \\
\hline
\end{tabular}

Table 32. Students' opinion about the material value assigned to an artwork.

\begin{tabular}{llcccc}
\hline & Frequency & Percent & Valid Percent & Cumulative Percent \\
\hline \multirow{2}{*}{ Valid } & Totally Disagree & 3 & 2.4 & 2.4 & 2.4 \\
& Disagree & 13 & 10.3 & 10.3 & 12.7 \\
& Undecided & 41 & 32.5 & 32.5 & 45.2 \\
& Agree & 47 & 37.3 & 37.3 & 82.5 \\
& Totally Agree & 22 & 17.5 & 17.5 & 100.0 \\
& Total & 126 & 100.0 & 100.0 & \\
\hline
\end{tabular}

indicated positive response, $7.9 \%$ indicated negative response and $16.7 \%$ was undecided about this item. Nevertheless, there were not any students rejecting this item with an absolute language (Table 31).

Item 4: I think the material value assigned to an artwork commoditizes the art.

This item questions the relationship between the art work and money in meta esthetics. Of the participant students, $54.8 \%$ indicated positive response and agreed that money commoditizes art; $32.5 \%$ were undecided about this item and $12.7 \%$ disagreed about this opinion (Table 32).

Item 5: The objective of making money draws the artist away from artistic creativity.

This item was included to point out that creativity did not have a material value. Of the participant students, $59.9 \%$ indicated that the objective of making money has drawn the artists away from creativity; $23.8 \%$ was undecided in this item and $16.7 \%$ indicated that artistic creativity was not deflated by ambition to make money (Table 33). 
Table 33. Students' opinion about creativity not having a material value.

\begin{tabular}{llcccc}
\hline & Frequency & Percent & Valid Percent & Cumulative Percent \\
\hline Valid & Totally Disagree & 14 & 11.1 & 11.1 & 11.1 \\
& Disagree & 7 & 5.6 & 5.6 & 16.7 \\
Undecided & 30 & 23.8 & 23.8 & 40.5 \\
Agree & 54 & 42.9 & 42.9 & 83.3 \\
Totally Agree & 21 & 16.7 & 16.7 & 100.0 \\
Total & 126 & 100.0 & 100.0 & \\
\hline
\end{tabular}

Table 34. Students' opinion about the most remarkable difference between an artwork and design product.

\begin{tabular}{llllll}
\hline & Frequency & Percent & Valid Percent & Cumulative Percent \\
\hline Valid & Totally Disagree & 2 & 1.6 & 1.6 & 1.6 \\
& Disagree & 18 & 14.3 & 14.3 & 15.9 \\
Undecided & 25 & 19.8 & 19.8 & 35.7 \\
Agree & 53 & 42.1 & 42.1 & 77.8 \\
Totally Agree & 28 & 22.2 & 22.2 & 100.0 \\
Total & 126 & 100.0 & 100.0 & \\
\hline
\end{tabular}

Item 6: The most remarkable difference between an artwork and design product is uniqueness of the design product.

This item points out the most remarkable difference between an artwork and a design product. Of the participant students, $64.3 \%$ indicated that they knew about this difference; $15.9 \%$ indicated uniqueness of artwork and 19.8 was undecided in this item (Table 34).

\section{Cross tables}

\section{Section Item 1- Question 9}

$\mathrm{H}_{0}$ : There are no correlations between the statements "The courses about art and design had contents that were able to teach me artistic design principles both theoretically and practically" and "Does the area you are studying currently meet your expectations?"

$\mathrm{H}_{1}$ : There is a correlation between the statements "The courses about art and design had contents that were able to teach me artistic design principles both theoretically and practically" and "Does the area you are studying currently meet your expectations?"

$\mathrm{H}_{0}$ was rejected since $\mathrm{P}=0.001<\alpha=0.05$. There is a correlation between the statements "The courses about art and design had contents able to teach me artistic design principles both theoretically and practically" and "Does the area you are studying meet your expectations?" Such a correlation was about $28 \%$.
When Tables 9 and 11 are evaluated closely, it is possible to indicate that about half of the participant students stated that the area they study met their expectations and the contents of the courses they took were both theoretically and practically satisfactory. This correlation was therefore apprehensible and having an overlapping character with each other (Table 35).

\section{Section Item 2- Question 9}

$\mathrm{H}_{0}$ : There are no correlations between the statements "The art education courses did not have contents in which I can use my creativity and composition knowledge" and "Does the area you are studying currently meet your expectations?"

$\mathrm{H}_{1}$ : There is a correlation between the statements "The art education courses did not have contents in which I can use my creativity and composition knowledge" and "Does the area you are studying meet your expectations?"

$\mathrm{H}_{0}$ was not rejected since $\mathrm{P}=0.155>\alpha=0.05$. There are no correlations between the statements "The art education courses did not have contents in which I can use my creativity and composition knowledge" and "Does the area you are studying meet your expectations?"

Considering Tables 9 and 12, the case suddenly turned into a different state. This time the participant students indicated the insufficiency of the course contents in developing their creativeness - the ratio was almost half 
Table 35. Correlation between the courses studied and meeting of students' expectations both theoretically and practically.

\begin{tabular}{|c|c|c|c|}
\hline \multicolumn{4}{|c|}{ Correlations } \\
\hline & & Area-expect. & $2-1$ \\
\hline \multirow[t]{6}{*}{$\begin{array}{l}\text { Spearman's } \\
\text { rho }\end{array}$} & $\begin{array}{l}\text { Correlation } \\
\text { Coefficient }\end{array}$ & 1.000 & $.286^{* *}$ \\
\hline & Sig. (2-tailed) & . & .001 \\
\hline & $\mathrm{N}$ & 126 & 126 \\
\hline & $\begin{array}{l}\text { Correlation } \\
\text { Coefficient }\end{array}$ & $-.286^{* *}$ & 1.000 \\
\hline & Sig. (2-tailed) & .001 & . \\
\hline & $\mathrm{N}$ & 126 & 126 \\
\hline
\end{tabular}

${ }^{* *}$. Correlation is significant at the 0.01 level (2-tailed).

Table 36. Correlation between art education courses does not have contents in which I can use my creativity and composition knowledge and meeting your expectations.

\begin{tabular}{|c|c|c|c|}
\hline \multicolumn{4}{|c|}{ Correlations } \\
\hline & & Area-expect. & $2-2$ \\
\hline \multirow[t]{6}{*}{$\begin{array}{l}\text { Spearman's } \\
\text { rho }\end{array}$} & $\begin{array}{l}\text { Correlation } \\
\text { Coefficient }\end{array}$ & 1.000 & .127 \\
\hline & Sig. (2-tailed) & . & .155 \\
\hline & $N$ & 126 & 126 \\
\hline & $\begin{array}{l}2 \_2 \text { Correlation } \\
\text { Coefficient }\end{array}$ & .127 & 1.000 \\
\hline & Sig. (2-tailed) & .155 & . \\
\hline & $N$ & 126 & 126 \\
\hline
\end{tabular}

of the students- but they were still satisfied with their expectations from the study program. Although such a finding seems like there is an inconsistency in students' opinions, the term "creativity" added to the item might be effective in this result (Table 36).

\section{Section Item 4 - Question 9}

$\mathrm{H}_{0}$ : There are no correlations between the statements "I think we have not received sufficient education about the significance and necessity that esthetic values should bear the characteristics of our culture" and "Does the area you are studying currently meet your expectations?" $\mathrm{H}_{1}$ : There is a correlation between the statements "I think we have not received sufficient education about the significance and necessity that esthetic values should bear the characteristics of our culture" and "Does the area you are studying meet your expectations?"
Table 37. Correlation between sufficient education on the significance and necessity of esthetic values and it meeting your expectations.

\begin{tabular}{llll}
\hline \multicolumn{5}{c}{ Correlations } & & \\
\hline & & $\begin{array}{l}\text { Area- } \\
\text { expect. }\end{array}$ & $\mathbf{2 - 4}$ \\
\hline $\begin{array}{l}\text { Spearman' } \\
\text { s rho }\end{array}$ & Correlation & 1.000 & $.229^{* *}$ \\
& Coefficient & & \\
& Sig. (2-tailed) &. & .010 \\
& $\mathrm{~N}$ & 126 & 126 \\
& Correlation & $.229^{* *}$ & 1.000 \\
& Coefficient & & \\
& Sig. (2-tailed) & .010 &. \\
& $\mathrm{~N}$ & 126 & 126 \\
\hline
\end{tabular}

$H_{0}$ was rejected since $P=0.010<\alpha=0.05$. There is a correlation between the statements "I think we have not received sufficient education about the significance and necessity that esthetic values should bear the characteristics of our culture" and "Does the area you are studying currently meet your expectations?" Such a correlation was about $23 \%$.

Similarly in this comparison, half of the participant students indicated an opinion about insufficiency of esthetic value education, but they still exhibited an attitude that their field expectations were met (Table 37 ).

\section{Section Item 5 - Question 9}

$\mathrm{H}_{0}$ : There are no correlations between the statements "I think art educators exhibited sufficient sincerity and sensitivity in art education" and "Does the area you are studying currently meet your expectations?"

$\mathrm{H}_{1}$ : There is a correlation between the statements "I think art educators exhibited sufficient sincerity and sensitivity in art education" and "Does the area you are studying currently meet your expectations?"

$\mathrm{H}_{0}$ was rejected since $\mathrm{P}=0.001<\alpha=0.05$. There is a correlation between the statements "I think art educators exhibited sufficient sincerity and sensitivity in art education" and "Does the area you are studying currently meet your expectations?" Such a correlation was about $28 \%$.

Considering Tables 9 and 15, the resultant values, as it was also indicated in Table 41, were negative but indicating a correlation. Together with undecided ones, $40.9 \%$ did not find the sincerity and sensitivity of the educators sufficient, but the majority still indicated that the study program have met their expectations (Table 38). 
Table 38. Correlations between art educators exhibited sufficient sincerity and sensitivity in art education the area you are studying currently meet your expectations.

\begin{tabular}{llll}
\hline \multicolumn{5}{c}{ Correlations } & \\
\hline & & $\begin{array}{l}\text { Area- } \\
\text { expect. }\end{array}$ & $2-5$ \\
\hline $\begin{array}{l}\text { Spearman } \\
\text { 's rho }\end{array}$ & Correlation & 1.000 & $-.285^{* *}$ \\
& Coefficient & & \\
& Sig. (2-tailed) &. & .001 \\
& $\mathrm{~N}$ & 126 & 126 \\
& Correlation & $-.285^{* *}$ & 1.000 \\
& Coefficient & & \\
& Sig. (2-tailed) & .001 &. \\
& $\mathrm{~N}$ & 126 & 126 \\
\hline
\end{tabular}

**. Correlation

Table 39. Correlations between art and design had contents that can teach me artistic design principles both theoretically and practically and art education courses not having contents in which I can use my creativity and composition knowledge

\begin{tabular}{rrrr}
\hline \multicolumn{3}{l}{ Correlations } & \\
\hline & $\mathbf{2 - 1}$ & $\mathbf{2 - 2}$ \\
\hline Spearman's rho 2_1 Correlation Coefficient & 1.000 & -.167 \\
& Sig. (2-tailed) &. & .062 \\
$\mathrm{~N}$ & 126 & 126 \\
2_2 & Correlation Coefficient & -.167 & 1.000 \\
& Sig. (2-tailed) & .062 &. \\
$\mathrm{~N}$ & 126 & 126 \\
\hline
\end{tabular}

\section{Section Item 1- II. Section Item 2}

$\mathrm{H}_{0}$ : There are no correlations between the statements "The courses about art and design had contents that were able to teach me artistic design principles both theoretically and practically" and "The art education courses did not have contents in which I can use my creativity and composition knowledge".

$\mathrm{H}_{1}$ : There is a correlation between the statements "The courses about art and design had contents that are able to teach me artistic design principles both theoretically and practically" and "The art education courses did not have contents in which I can use my creativity and composition knowledge".

$\mathrm{H}_{0}$ was not rejected since $\mathrm{P}=0.062>\alpha=0.05$. There are no correlations between the statements "The courses about art and design had contents able to teach me artistic design principles both theoretically and practically" and "The art education courses did not have contents in which I can use my creativity and composition knowledge".

In Table 13, 57.1\% indicated positive opinions about the sufficiency of course contents. In Table 14, 56.4\% indicated an opinion about problematic nature of the contents in utilizing creativity. These two opinions were conflicting among themselves (Table 39).

\section{Section Item 1- II. Section Item 3}

$\mathrm{H}_{0}$ : There are no correlations between the statements "The courses I took about art and design had contents that were able to teach me artistic design principles both theoretically and practically" and "I think we took qualified art and design courses for us as an art producer or consumer to play the role of an artist or a designer properly".

$\mathrm{H}_{1}$ : There is a correlation between the statements "The courses about art and design had contents that were able to teach me artistic design principles both theoretically and practically" and "I think we took qualified art and design courses for us as an art producer or consumer to play the role of an artist or a designer properly".

$\mathrm{H}_{0}$ was rejected since $\mathrm{P}=0.000<\alpha=0.05$. There is a correlation between the statements "The courses about art and design had contents that were able to teach me artistic design principles both theoretically and practically" and "I think we took qualified art and design courses for us as an art producer or consumer to play the role of an artist or a designer properly". Such a correlation was about $54 \%$.

In Table 13, 57.1\% indicated positive opinion about the sufficiency of course contents; In Table 15 on the other hand, $56.4 \%$ of the students indicated a parallel opinion about the qualified art and design education they received. Thus, a strong correlation was observed between these two items (Table 40).

\section{Section Item 1 - II. Section Item 4}

$\mathrm{H}_{0}$ : There are no correlations between the statements "The courses about art and design had contents that were able to teach me artistic design principles both theoretically and practically" and "I don't think we have received sufficient education about the significance and necessity that esthetic values should bear the characteristics of our culture".

$\mathrm{H}_{1}$ : There is a correlation between the statements "The courses about art and design had contents that were able to teach me artistic design principles both theoretically and practically" and "I don't think we have received sufficient education about the significance and necessity 
Table 40. Correlations between the courses I took about art and design contents that were able to teach me artistic design principles both theoretically and practically" and "I think we took qualified art and design courses for us as an art producer or consumer to play the role of an artist or a designer properly.

\begin{tabular}{cccc}
\hline \multicolumn{3}{l}{ Correlations } & \\
\hline \multicolumn{3}{c}{ 2-1 } & 2-3 \\
\hline Spearman's rho 2_1 & Correlation Coefficient & 1.000 & $.540^{* *}$ \\
& Sig. (2-tailed) &. & .000 \\
$\mathrm{~N}$ & 126 & 126 \\
2_3 Correlation Coefficient & $.540^{* *}$ & 1.000 \\
& Sig. (2-tailed) & .000 &. \\
$\mathrm{~N}$ & 126 & 126 \\
\hline
\end{tabular}

${ }^{\star *}$. Correlation is significant at the 0.01 level (2-tailed).

that esthetic values should bear the characteristics of our culture".

$\mathrm{H}_{0}$ was not rejected since $\mathrm{P}=0.519>\alpha=0.05$. There are no correlations between the statements "The courses about art and design had contents that were able to teach me artistic design principles both theoretically and practically" and "I don't think we have received sufficient education about the significance and necessity that esthetic values should bear the characteristics of our culture".

A conflict was identified between the positive attitudes of the majority of the students about course contents (Table 13) and negative attitudes of almost half of the students about esthetic value education (Table 41).

\section{Section Item 4- II. Section Item 6}

$\mathrm{H}_{0}$ : There are no correlations between the statements "I don't think we have received sufficient education about the significance and necessity that esthetic values should bear the characteristics of our culture" and "I don't think esthetic and meta-esthetic topics were sufficiently placed in course contents of education program".

$\mathrm{H}_{1}$ : There is a correlation between the statements "I don't think we have received sufficient education about the significance and necessity that esthetic values should bear the characteristics of our culture" and "I don't think esthetic and meta-esthetic topics were sufficiently placed in course contents of education program".

$\mathrm{H}_{0}$ was rejected since $\mathrm{P}=0.000<\alpha=0.05$. There is a correlation between the statements "I don't think we have received sufficient education about the significance and necessity that esthetic values should bear the characteristics of our culture" and "I don't think esthetic and meta esthetic topics were sufficiently placed in course
Table 41. Correlation between the courses about art and design had contents that were able to teach me artistic design principles both theoretically and practically" and "I don't think we have received sufficient education about the significance and necessity that esthetic values should bear the characteristics of our culture

\begin{tabular}{cccc}
\hline \multicolumn{3}{c}{ Correlations } & \\
\hline & & 2-3 & 2-4 \\
\hline Spearman's rho 2_3 & Correlation Coefficient & 1.000 & -.059 \\
& Sig. (2-tailed) &. & .512 \\
$\mathrm{~N}$ & 126 & 126 \\
$2 \_4$ & Correlation Coefficient & -.059 & 1.000 \\
& Sig. (2-tailed) & .512 &. \\
$\mathrm{~N}$ & 126 & 126 \\
\hline
\end{tabular}

Table 42. Correlation between "I don't think we have received sufficient education about the significance and necessity that esthetic values should bear the characteristics of our culture" and "I don't think esthetic and meta esthetic topics were sufficiently placed in course contents of education program.

\begin{tabular}{lcll}
\hline \multicolumn{4}{c}{ Correlations } \\
\hline & & & \\
\hline Spearman's rho & 3-6 & \\
& 2_4 Correlation Coefficient & 1.000 & -.053 \\
& Sig. (2-tailed) &. & .558 \\
& $\mathrm{~N}$ & 126 & 126 \\
& 3_6 Correlation Coefficient & -.053 & 1.000 \\
& Sig. (2-tailed) & .558 &. \\
& $\mathrm{~N}$ & 126 & 126 \\
\hline
\end{tabular}

contents of education program". Such a correlation was about $41 \%$

Student attitudes about the insufficiency of esthetic value education $(50.8 \%$ ) (Table 14 ) and insufficiency of esthetic and meta-esthetic content of the programs (42\%) (Table 14) were considered as conflicting opinions. In this case, $58 \%$ was thinking that esthetic and meta esthetic courses were sufficiently placed in educational programs. On the other hand, they were also thinking that esthetic value education was not sufficiently placed in contents (Table 42).

\section{Section Item 6 - IV. Section Item 1}

$\mathrm{H}_{0}$ : There are no correlations between the statements "I don't think esthetic and meta esthetic topics were sufficiently placed into course contents of education program" and "I hear the concept of "meta esthetics" for the first time". 
Table 43. Correlations between the statements "I don't think esthetic and meta esthetic topics were sufficiently placed into course contents of education program" and "I hear the concept of "meta esthetics" for the first time

\begin{tabular}{|c|c|c|c|}
\hline \multicolumn{4}{|c|}{ Correlations } \\
\hline & & $2-6$ & 4-1 \\
\hline Spearman's rho 2_6 Correlation Co & t 1.000 & -.146 & \\
\hline Sig. (2-tailed) & . & .104 & \\
\hline $\mathrm{N}$ & 126 & 126 & \\
\hline 4_1 Correlation Co & $\mathrm{t}-.146$ & 1.000 & \\
\hline Sig. (2-tailed) & .104 & . & \\
\hline $\mathrm{N}$ & 126 & 126 & \\
\hline
\end{tabular}

Table 44. Correlations between the statements "I don't think we have received sufficient education about the significance and necessity that esthetic values should bear the characteristics of our culture" and "I hear the concept of "meta esthetics" for the first time.

\begin{tabular}{cccc}
\hline \multicolumn{3}{l}{ Correlations } \\
\hline \multicolumn{2}{c}{$\mathbf{2 - 4}$} & \multicolumn{1}{c}{$\mathbf{4 - 1}$} \\
\hline Spearman's rho 2_4 & Correlation Coefficient & 1.000 & .030 \\
& Sig. (2-tailed) &. & .739 \\
$\mathrm{~N}$ & 126 & 126 \\
$4 \_1$ Correlation Coefficient & .030 & 1.000 \\
& Sig. (2-tailed) & .739 &. \\
$\mathrm{~N}$ & 126 & 126 \\
\hline
\end{tabular}

$\mathrm{H}_{1}$ : There is a correlation between the statements "I don't think esthetic and meta esthetic topics were sufficiently placed into course contents of education program" and "I hear the concept of "meta esthetics" for the first time". $\mathrm{H}_{0}$ was rejected since $P=0.104<\alpha=0.05$. There is a correlation between the statements "I don't think esthetic and meta esthetic topics were sufficiently placed into course contents of education program" and "I hear the concept of "meta esthetics" for the first time". Such a correlation was about $14 \%$.

In Table 16, 58\% was thinking that esthetic and metaesthetic topics were included in course contents sufficiently. Besides, in Table $23,56.4 \%$ indicated they have heard the concept of meta esthetics for the first time. Such a correlation was in negative direction and it is a contradictory correlation (Table 43).

\section{Section Item 4 - IV. Section Item 1}

$\mathrm{H}_{0}$ : There are no correlations between the statements "I don't think we have received sufficient education about the significance and necessity that esthetic values should bear the characteristics of our culture" and "I hear the concept of "meta esthetics" for the first time".

$\mathrm{H}_{1}$ : There is a correlation between the statements "I don't think we have received sufficient education about the significance and necessity that esthetic values should bear the characteristics of our culture" and "I hear the concept of "meta esthetics" for the first time".

$H_{0}$ was not rejected since $P=0,739>\alpha=0,05$. There are no correlations between the statements "I don't think we have received sufficient education about the significance and necessity that esthetic values should bear the characteristics of our culture" and "I hear the concept of "meta esthetics" for the first time".

In Table 14, while $49.2 \%$ of the students was indicating insufficiency of education about esthetic values, $56.4 \%$ indicated that they heard about the concept of meta esthetics for the first time. However, $50.8 \%$ found the esthetic value education sufficient. Such a case again is conflicting (Table 44).

\section{Section Item 1 - III. Section Item 2}

$\mathrm{H}_{0}$ : There are no correlations between the statements "I don't feel uncomfortable buying products for which advertisement is made by exaggerating or distorting their characteristics although they are "nice" according to my senses" and "Appearance of a product to be purchased is more important than its functions".

$\mathrm{H}_{1}$ : There is a correlation between the statements "I don't feel uncomfortable buying products for which advertisement is made by exaggerating or distorting their characteristics although they are "nice" according to my senses" and "Appearance of a product to be purchased is more important than its functions".

$H_{0}$ was not rejected since $P=0.230>\alpha=0.05$. There aren't any correlations between the statements "I don't feel uncomfortable buying products for which advertise- 
Table 45. Correlations between the statements "I don't feel uncomfortable buying products for which advertisement is made by exaggerating or distorting their characteristics although they are "nice" according to my senses" and "Appearance of a product to be purchased is more important than its functions.

\begin{tabular}{llll}
\hline \multicolumn{1}{l}{ Correlations } & \multicolumn{1}{c}{ 3-1 } & \multicolumn{3}{l}{$\mathbf{3 - 2}$} \\
\hline \multicolumn{1}{l}{ Spearman's rho 3_1 } & Correlation Coefficient & 1.000 & .108 \\
& Sig. (2-tailed) &. & .230 \\
$\mathrm{~N}$ & 126 & 126 \\
3_2 Correlation Coefficient & .108 & 1.000 \\
& Sig. (2-tailed) & .230 &. \\
$\mathrm{~N}$ & 126 & 126 \\
\hline
\end{tabular}

ment is made by exaggerating or distorting their characteristics although they are "nice" according to my senses" and "Appearance of a product to be purchased is more important than its functions".

In Table 17, $51.2 \%$ of the students indicated that they don't feel uncomfortable buying products for which advertisement is made by exaggerating or distorting their characteristics although they "nice" according to my senses. Besides, in Table 18, 40.07\% indicated the significance of functions of a product. Such opinions are also conflicting (Table 45).

\section{Section Item 5 - III. Section Item 6}

$\mathrm{H}_{0}$ : There are no correlations between the statements "Because of art and design education I received, I look for initially the esthetic integrity and uniqueness in a product I purchase" and "I think the institutions providing basic art/design education and raising artists/designers are insufficient in raising conscious art consumers".

$\mathrm{H}_{1}$ : There is a correlation between the statements "Because of art and design education I received, I look for initially the esthetic integrity and uniqueness in a product I purchase" and "I think the institutions providing basic art/design education and raising artists/designers are insufficient in raising conscious art consumers".

$\mathrm{H}_{0}$ was rejected since $\mathrm{P}=0.018<\alpha=0.05$. There is a correlation between the statements "Because of art and design education I received, I look for initially the esthetic integrity and uniqueness in a product I purchase" and "I think the institutions providing basic art/design education and raising artists/designers are insufficient in raising conscious art consumers". Such a correlation was about $21 \%$.

In Table 21, 78.2\% great majority indicated that they prioritized esthetic integrity and specificity in purchasing a
Table 46. Because of art and design education I received, I look for initially the esthetic integrity and uniqueness in a product I purchase" and "I think the institutions providing basic art/design education and raising artists/designers are insufficient in raising conscious art consumers.

\begin{tabular}{llll}
\hline \multicolumn{1}{l}{ Correlations } & & & \\
\hline \multicolumn{2}{l}{ Spearman's rho 3_5 } & \multicolumn{3}{l}{ 3-6 } \\
\hline & Sig. (2-tailed) &. & .018 \\
$\mathrm{~N}$ & 126 & 126 \\
3_6 Correlation Coefficient & $.210^{*}$ & 1.000 \\
& Sig. (2-tailed) & .018 &. \\
$\mathrm{~N}$ & 126 & 126 \\
\hline
\end{tabular}

*. Correlation is significant at the 0.05 level (2-tailed).

product however $52.4 \%$ found the institutions providing basic art/design education and raising artist/designer are insufficient in raising conscious art consumers. About half of the remaining students thought contrarily. That explains the significant relationship between the items (Table 46).

\section{Section Item 2 - IV. Section Item 3}

$\mathrm{H}_{0}$ : There are no correlations between the statements "I think esthetic appearance and functionality are equally and highly important in design of every use intended product" and "In a product produced to express myself, I don't care about the interests and needs of the crowd with which I share that product".

$\mathrm{H}_{1}$ : There is a correlation between the statements "I think esthetic appearance and functionality are equally and highly important in design of every intended use product" and "In a product produced to express myself, I don't care about the interests and needs of the crowd with which I share that product".

$\mathrm{H}_{0}$ was not rejected since $\mathrm{P}=0.128>\alpha=0.05$. There aren't any correlations between the statements "I think esthetic appearance and functionality are equally and highly important in design of every intended use product" and "In a product produced to express myself, I don't care about the interests and needs of the mass with which I share that product".

In Table 24, $76.2 \%$ of the students preferred appearance over functions. On the other hand in Table $25,42.8$ of the students indicated that they didn't care about the functions in production. It was expected that this item should have higher rates as parallel to the previous item. Student attitudes were also found conflicting here (Table 47). 
Table 47. Correlations between the statements "I think esthetic appearance and functionality are equally and highly important in design of every use intended product" and "In a product produced to express myself, I don't care about the interests and needs of the crowd with which I share that product.

\begin{tabular}{|c|c|c|}
\hline \multicolumn{3}{|l|}{ Correlations } \\
\hline & 4-2 & 4-3 \\
\hline \multicolumn{3}{|c|}{ Spearman's rho 4_2 Correlation Coefficient 1.000 -.136 } \\
\hline Sig. (2-tailed) & . & .128 \\
\hline $\mathrm{N}$ & 126 & 126 \\
\hline 4_3 Correlation Co & -.136 & 1.000 \\
\hline Sig. (2-tailed) & .128 & . \\
\hline $\mathrm{N}$ & 126 & 126 \\
\hline
\end{tabular}

\section{Section Item 5 - V. Section Item 1}

$\mathrm{H}_{0}$ : There are no correlations between the statements "It is possible to direct people without being noticed and to impose the elements of a culture on them" and "I think that creating a need for anything requires creativity of people as well".

$\mathrm{H}_{1}$ : There is a correlation between the statements "It is possible to direct people without being noticed and to impose the elements of a culture on them" and "I think creating a need for anything requires creativity of people as well".

$\mathrm{H}_{0}$ was rejected since $\mathrm{P}=0.000<\alpha=0.05$. There is a correlation between the statements "It is possible to direct people without being noticed and to impose the elements of a culture on them" and "I think that creating a need for anything requires creativity of people as well." Such a correlation was about $39 \%$.

Of the participant students, $85.4 \%$ approved the esthetic characteristic of meta esthetics to purchaser (Table 27) and $84.1 \%$ indicated that creativeness was effective in manipulations toward the human needs. Therefore, the correlation between them was significant (Table 48).

\section{Section Item 5 - V. Section Item 2}

$\mathrm{H}_{0}$ : There are no correlations between the statements "It is possible to direct people without being noticed and to impose the elements of a culture on them" and "I think knowledge of metaesthetics by creative individuals is both necessary and significant in culture transfer".

$\mathrm{H}_{1}$ : There is a correlation between the statements "It is possible to direct people without being noticed and to impose the elements of a culture on them" and "I think knowledge of metaesthetics by creative individuals is both necessary and significant in culture transfer".
Table 48. Correlations between the statements "It is possible to direct people without being noticed and to impose the elements of a culture on them" and "I think that creating a need for anything requires creativity of people as well.

\begin{tabular}{|c|c|c|}
\hline \multicolumn{3}{|l|}{ Correlations } \\
\hline & $4-5$ & $5-1$ \\
\hline \multicolumn{3}{|c|}{ Spearman's rho 4_5 Correlation Coefficient $1.000 .395^{* *}$} \\
\hline Sig. (2-tailed) & . & .000 \\
\hline $\mathrm{N}$ & 126 & 126 \\
\hline \multicolumn{3}{|c|}{ 5_1 Correlation Coefficient $.395^{* *} 1.000$} \\
\hline Sig. (2-tailed) & .000 & . \\
\hline $\mathrm{N}$ & 126 & 126 \\
\hline
\end{tabular}

Table 49. It is possible to direct people without being noticed and to impose the elements of a culture on them" and "I think knowledge of metaesthetics by creative individuals is both necessary and significant in culture transfer

\begin{tabular}{llll}
\hline \multicolumn{1}{l}{ Correlations } & & \\
\hline \multicolumn{1}{l}{ Spearman's rho 4_5 } & \multicolumn{1}{c}{$\mathbf{5 - 2}$} \\
\hline & Sig. (2-tailed) &. & .159 \\
$\mathrm{~N}$ & 126 & 126 \\
5_2 Correlation Coefficient & .126 & 1.000 \\
& Sig. (2-tailed) & .159 &. \\
$\mathrm{~N}$ & 126 & 126 \\
\hline
\end{tabular}

$H_{0}$ was not rejected since $P=0,159>\alpha=0.05$. There are no correlations between the statements "It is possible to direct people without being noticed and to impose the elements of a culture on them" and "I think knowledge of metaesthetics by creative individuals is both necessary and significant in culture transfer".

Of the participant students, $85.4 \%$ indicated that it was possible to direct people without being noticed and to impose the elements of a culture on them (Table 27) and $70.7 \%$ indicated that knowledge of metaesthetics by creative individuals was both necessary and significant in culture transfer (Table 30). These two statements indicated the same opinions and they were accepted independently by the majority of the students (Table 49).

\section{Section Item 4 - V. Section Item 5}

$\mathrm{H}_{0}$ : There are no correlations between the statements "I think the material value assigned to an artwork commoditizes the art" and "The objective of making 
Table 50. Correlations between the statements "I think the material value assigned to an artwork commoditizes the art" and "The objective of making money draws the artist away from artistic creativity

\begin{tabular}{|c|c|c|c|}
\hline \multicolumn{4}{|l|}{ Correlations } \\
\hline & & $5-4$ & $5-5$ \\
\hline \multirow[t]{6}{*}{ Spearman's rho } & 5_4 Correlation Coefficient & 1.000 & .066 \\
\hline & Sig. (2-tailed) & . & .461 \\
\hline & $\mathrm{N}$ & 126 & 126 \\
\hline & 5_5 Correlation Coefficient & .066 & 1.000 \\
\hline & Sig. (2-tailed) & .461 & \\
\hline & $\mathrm{N}$ & 126 & 126 \\
\hline
\end{tabular}

money draws the artist away from artistic creativity". $\mathrm{H}_{1}$ : There is a correlation between the statements "I think the material value assigned to an artwork commoditizes the art" and "The objective of making money draws the artist away from artistic creativity".

$\mathrm{H}_{0}$ was not rejected since $\mathrm{P}=0.461>\alpha=0.05$. There aren't any correlations between the statements "I think the material value assigned to an artwork commoditizes the art" and "The objective of making money draws the artist away from artistic creativity".

Of the participant students, $54.8 \%$ indicated that the material value assigned to an artwork commoditizes the art (Table 32) and $59.6 \%$ indicated that the objective of making money draws the artists away from artistic creativity (Table 33). Considering student opinions about money-meta-art relationship, they exhibited different and even conflicting attitudes from each other (Table 50).

\section{CONCLUSION AND SUGGESTIONS}

The following conclusions can be drawn from the statements provided by the students about attitude scales:

Majority of the participant students were females of ages between 22-25 years and most of them were enrolled in freshman ( $1^{\text {st }}$ class) year at Interior Architecture and Environmental Design Department (Tables 1, 2, 3 and 4). With regard to educational levels of parents, while fathers mostly had undergraduate and graduate level education, mothers mostly had high school education (Tables 5 and $6)$.

The courses in which the students were the least successful were in order: English, Esthetics, and Art History. The place of the two of four disciplines of art/design education such as Esthetic and Art History is extremely striking and this has characteristic to affect all results.

It was determined that most of the students agreed on most items almost as polarized and this situation led to conflicting results in many tables. Accordingly, it was determined that the students agreed on the matters of the specificity of art or design product, multiplication of design product and advertising; however despite all the recognized knowledge, they developed an attitude to bring themselves forward or to disregard all ethical values for the sake of making money.

One of the striking conclusions has shown itself in judgments of university students about art educators. While the students' responses were not consistent about whether art educators were adequately sensitive and sincere in teaching art, substantial majority, ended with negative response (Table-14). In this case, unsatisfied expectations of the students can be considered as a negative attitude. The failure of faculty members to express their sincerity to the students was mainly because of heavy course loads and time limitations. Decreasing the course loads or increasing working hours may result in more effective relationships between the students and the faculty members.

Art students still have doubts about the nature of art courses (Table-12). Thus, majority of them expressed the instable nature of art courses and the rest were in dilemma about the sufficiency of art courses. Thus, art education curriculum should be rearranged.

Such outcomes brought forward initially the responsibility of higher educational institutes with regard to quality and practical characteristics of the education they provided and ultimately the responsibility of families in every case affecting the students.

The student failures in esthetic and art history classes supplementing art/design education should also be carefully evaluated and relevant measures should be taken. Negative attitudes toward the instructors and course contents might definitely be effective in such outcomes, but considering the age group of the students, they were mostly between 22-25 years of age. They were at ages to be able to mentally synthesize the theoretical knowledge however their attitudes putting the ethics behind the publicity and money is daunting. A value training starting from the lowest levels should be provided on this matter. Higher educational institutes of art and design faculties providing sensitivity education should focus more on esthetics, esthetic values, art history and critical theories. Otherwise, future instructors, artists, designers and even parents will turn into ethicallycrippled generations and they will put exchange value of items over any values in time.

Physical and technological equipment to provide practical opportunities to students, and instructor attitudes, controlled, liberal, and cooperative and solid education and training methods will be crucial and mandatory for raising conscious youths. It is thought that inner happiness and sensual satisfaction of instructors from their professions is the primary effect and later on finding, discovering and using modern ways of awareness and protection and transfer to other generations of 
national values will enable satisfaction of instructors secondarily. There are several internal and international publications on this issue. The common denominator of all these works is happiness, transformation, adaptation and motivation. This basic pattern is regarded as components to bring success to instructors; and it is suggested that providing these can be achieved only by a conscious programming and classification.

A higher education, which is conscious about cultural matters, and producing and consuming consciously, and which can control the entire media and most importantly can adapt their own self values and customs and make generalization, is the right of all youngsters. To achieve this, the present study and similar studies will illuminate us, and provide comparison opportunity and will allow us to make an evaluation and will open new ways. A comparison of this study and the doctorate thesis study, which was done previously and unpublished, will be made. It is hoped that new doors and study areas will be opened to youngsters in meta esthetic and objectivation matters.

\section{REFERENCES}

Boydaş N (2006). Introduction to Art Criticism. ( ${ }^{\text {st }}$ Issue) Ankara: Gunduz Education and Publication.
Haug WF (1997). Criticism of Meta-Esthetics (Translated by: Ayşe Gul). $\left(1^{\text {st }}\right.$ Issue) İstanbul: Spartakus Publications. (Original work was published in 1986).

Peşkersoy E (2009). Effects Of Demographic Characteristics and Art Education On Student Consciousness About Meta Esthetics, Ankara/TR: Unpublished Ph.D thesis, Gazi University, Institute of Educational Sciences.

Ranciére J (2001). Esthetic Unconsciousness. (Translated by: Kenan Sarialioglu) (1st Edition). Izmir: ARA-lik Publishing

Robinson K (2008). Creativity Overcome the Limits of Mind. (Translated by: Nihal Geydan Koldaş) (2nd Edition). İstanbul: Kitap Publications.

Read H (1978). Art And Industry. (Translated by: Dr. Nigan Bayazit). Istanbul: ITU Press. (Original work was published in 1952).

Tdk, Great Turkish Dictionary, Web: http//www.tdk.gov.tr

Tunali I (1998). Esthetics. (5 $5^{\text {th }}$ Edition) Istanbul: Remzi Publishing.

Tunali I (2003). Marxist Esthetics. (3 ${ }^{\text {rd }}$ Edition) Istanbul: Analiz Publishing.

Tunali I (2009). Design Philosophy. ( $3^{\text {rd }}$ Issue) Istanbul: Yem Publishing.

Yildirim A, Simsek H (2000). Qualitative Research Methods in Social Sciences. ( $2^{\text {nd }}$ Edition) Ankara: Seckin Publishing. 